e-ISSN: 2518-2943

Universidad Nacional de Ingeniería

Facultad de Arquitectura
URL: www.camjol.info/index.php/arquitectura DOI: https://doi.org/10.5377/arquitectura.v6i12.13085 e-mail: rvarqui.mas@farq.uni.edu.ni

\title{
Arquitectura en los espacios de vida urbana y rural
}

\section{Architecture in urban and rural living spaces}

\author{
Mendoza Vidaurre, René ${ }^{1}$ \\ Mendoza Estrada, Jaren ${ }^{2}$ \\ ${ }^{1}$ Universidad Americana, Managua, Nicaragua \\ ${ }^{2}$ Universidad de Amberes y Wind of Peace Foundation, Managua, Nicaragua \\ 1rmvidaurre@gmail.com / https://orcid.org/0000-0002-3462-9507 \\ 295jaren@gmail.com / https://orcid.org/0000-0003-4755-5065
}

Recibido el 20 de agosto de 2021, aprobado el 27 de diciembre de 2021

RESUMEN | La salud y la arquitectura históricamente han generado cambios en el diseño de las ciudades y de las casas. Así en el s. XIX ante la crisis de la higiene y la aglomeración, ciudades de Londres, Barcelona o París cambiaron. La revolución de las casas con más concreto y metal, los closets en lugar de armarios y las cocinas abiertas. El rediseño de espacios públicos de ciudades y de oficinas. Y ahora el reto en los espacios rurales debido al cambio climático y en fase post covid-19.

PALABRAS CLAVE | Salud, arquitectura, espacios, post pandemia, rediseño, rural

ABSTRACT | Health and architecture have historically generated changes in the design of cities and houses. Thus, in the 19th century, faced with the crisis of hygiene and agglomeration, the cities of London, Barcelona or Paris changed. The revolution of houses with more concrete and metal, closets instead of cabinets and open kitchens. The redesign of public spaces in cities and offices. And now the challenge in rural spaces due to climate change and in the postcovid-19 phase.

KEYWORD | Health, architecture, spaces, post-pandemic, redesign, rural 


\section{Introducción}

Engelmann, Henderson y Lynteris (2019) editaron un libro sobre la relación entre las pestes y la arquitectura de ciudades y de las casas. En los tiempos del COVID-19 esa relación cobra actualidad. No es solo el sistema de salud que cura, también lo preventivo; en lo preventivo esta el diseño de la casa, la oficina, la ciudad y la comunidad rural donde vivimos. ¿Cómo diseñar ciudades, casas y comunidades que frenen los virus y enfermedades y alarguen la vida humana y natural?

Los autores somos hijo y Papá, el hijo que estudia arquitectura y lee desde el ángulo de su carrera el impacto que el covid-19 va generando. Y Papá que se mueve en el mundo rural observa que el tener más o menos dinero no hace diferencia en medidas de prevención ante las pandemias. En conversaciones hijo-padre nos damos cuenta que la arquitectura podría hacer diferencia en la vida de la mayoría de las personas, si además de servirle al dinero también estuviese al servicio de la humanidad.

En este artículo revisamos históricamente de cómo esa relación generó cambios en las ciudades y al interior de las casas, y de lo que se está haciendo actualmente ante el COVID-19. En ese marco notamos que la arquitectura, en cuanto a casas, está prácticamente al servicio de un 10\% de la población mundial. De hecho en las áreas rurales y barrios de las ciudades, la población raramente conoce a alguna persona que sea arquitecta. El mundo rural está desconectado de la arquitectura, más que como lugar de hobby o "casas de verano" o "casas de descanso" de algunas familias urbanas.

\section{La ventana histórica: arquitectura movida por la salud}

La salud pública y la arquitectura han contribuido a que la población viva más años. "En los últimos 150 años, la expectativa de vida ha aumentado de alrededor de 45 a 80 años y es justo afirmar que la mitad de eso se debe a la arquitectura y la ingeniería y la otra mitad, a la comunidad médica", Jakob Brandtberg Knudsen, decano de la escuela de arquitectura de la Real Academia de Bellas Artes, Dinamarca (BBC News Mundo, 2020) -Brandtberg tiene razón de cara a los países de Europa. En los últimos 150 años conocemos de grandes cambios en las ciudades del mundo y cambios al interior de las casas.

\section{- Revolución en las ciudades}

En el siglo XIX, Londres tuvo una crisis higiénica por la contaminación en el rio Támesis, que ocasionó dos grandes problemas, el Gran Hedor y el esparcimiento del cólera. Esto fue provocado por la cantidad de desechos residuales creada por una población con un crecimiento exponencial. Esos residuos desbordaron los pozos negros que inundaron las calles y terminaron en el rio. En 1858 el hedor empeoró y el gobierno buscó soluciones. Una solución vino de Joseph Bazalgette, quien propuso construir de forma paralela al rio, alcantarillas principales subterráneas de ladrillos para interceptar la salida de aguas residuales domiciliarias, y alcantarillas secundarias para interceptar las aguas residuales que fluían libremente por las calles. Las salidas de las redes enviaban el afluente rio abajo, y de ahí al mar. Con ello, Bazalgette consiguió eliminar el olor de la ciudad y sin que sea su propósito, con aquella acción, erradico el cólera en la ciudad. 
En el mismo siglo, en Barcelona, la fuerte limitación territorial de la ciudad hizo que continuase creciendo hacia arriba, edificando plantas sobre pisos ya existentes. En 1818 vivían en Barcelona 83,000 personas, y en 1850 ya eran más del doble, 187.000. Faltaban espacio e infraestructuras y las condiciones de salubridad eran pésimas. La ciudad colapsaba intramuros mientras que las afueras estaban llenas de campos desiertos. Ante esta situación un clamor popular crecía pidiendo a gritos derribar las murallas.

De ese movimiento surgió el llamado Plan Cerdá, que proyectó el Ensanche de Barcelona, un plan urbanístico de calles rectilíneas, paralelas y perpendiculares entre sí, formando unas cuadrículas tridimensionales llamadas manzanas. Barcelona se adaptaba al futuro y ensanchaba sus calles, habilitándolas para el uso de transporte público (tranvía, tren) o privado (carros y coches). Son los años de la fiebre modernista gracias a la burguesía catalana que encuentra, presionada por la insalubridad, en la nueva corriente arquitectónica una forma de satisfacer sus ansias de modernización y de manifestar, discretamente, su riqueza y su distinción.

A principios del mismo siglo XIX, la ciudad de París duplicó su densidad poblacional. El centro de la ciudad era caótico, abarrotado, oscuro, plagado de crímenes, peligroso e insalubre. No era raro encontrar 23 personas, adultos y niños, viviendo en una habitación de cinco metros cuadrados, menos de ocho por siete pies. Dentro de una ciudad llena de gente, los carros, carruajes y carretas apenas podían moverse. Las calles más anchas tenían solo cinco metros de ancho (16 pies) y las más angostas tenían solo un metro de ancho (tres pies). París estaba en un punto muerto y sus problemas de salud eran sistemáticas.

Napoleón III, autonombrado emperador de Francia, dirigió la mayor transformación urbana junto con Georges-Eugène Haussman. El Plan de Haussmann fue una intervención quirúrgica a partir de una combinación de una reforma sanitaria y un programa de embellecimiento en el centro creando una segregación social. Esto se se logró con la ampliación y creación de nuevas calles y avenidas para que sirvieran como base para la estructuración de sistemas viales que vincularan los barrios y estaciones de ferrocarriles con el centro. En calles anchas y rectas fluye más viento y entra más los rayos del sol.

En las tres ciudades la higiene fue el motor del cambio para poblaciones que se multiplican y se enferman en espacios reducidos, desorganizados y hacinados. Su mejoramiento en desagues y drenajes de pantanos, fue su respuesta a la constante amenaza de las bacterias.

\section{Revoluciones en casas}

Pequeñas mejorías también tuvieron grandes impactos. Agua limpia y manejo de aguas sucias para evitar la malaria o la fiebre amarilla. Ante la peste bubónica, que mató 12 millones de personas entre 1855 y 1959, reconstruyeron las casas con más concreto y metal para evitar las ratas que portaban dicha peste. Los clósets se impusieron en lugar de armarios porque éstos acumulaban polvo.

La cocina, en particular, ha sido lugar de grandes cambios. En el pasado, las casas tenían sus cocinas en un cuarto separado de las áreas sociales y de alimentación, lo que condenaba a las mujeres a encerrarse en espacios donde la insalubridad proliferaba. Margarethe Schütte-Lihotzky, según Phame (2013), presentó su diseño de cocina en Frankfurt a mediados de la década de 1920; era un diseño de cocina con dos objetivos en mente, optimizar el trabajo en la cocina para reducir el tiempo de cocción, y reducir el costo de construir cocinas decentemente equipadas. Aunque la 
cocina era pequeña (6 pies x 11 pies), apenas lo suficientemente grande como para que trabajara más de una persona, se convirtió en el estándar para la mayoría de los apartamentos de alquiler del siglo $\mathrm{XX}$.

Frank Lloyd Wright, según Phame (2013), dio otro paso de cambio, mucho más salubre: una cocina abierta. Propuso una cocina con una nueva distribución del espacio, democratizando incluso la participación de los miembros del hogar. Las mujeres ya no se limitaban a la cocina y los hombres comenzaron a asumir tareas en el hogar. Esta propuesta fue vista en sus diseños y se volvió el estándar de la casa suburbana y aun hoy en día se puede ver como la cocina se mantiene abierta a todas las otras áreas del hogar. Despues ha habido otros cambios espaciales y tecnológicos en la cocina, pero desde Margarethe, la cocina ha tenido un rol social en la vivienda, y se ha mantenido de esta manera con el título del "corazón del hogar".

La casa en su conjunto fue cambiando, en gran parte, gracias a la higiene. Colomina (2019) estudia como la tuberculosis llevó a que la arquitectura diseñara casas con espacios que eviten el polvo: "la enfermedad es lo que modernizó la arquitectura, no sólo los nuevos materiales y tecnologías". La arquitectura, para diseñar casas, se inspiró en los sanatorios para tuberculosis. La situación no era para menos, 1 de 7 en el mundo moría de tuberculosis, y en ciudades como París 1 de 3. No solo la estética, pero las enfermedades, cambiaron el diseño de las casas.

El polvo ha sido un problema de salud, por lo que las casas se han ido diseñando para evitar se acumule polvo, de ahí los armarios empotrados, muebles colgantes, superficies lisas... A ello se va uniendo el diseño de jardines y espacios abiertos.

\section{Rediseño de los espacios}

En los últimos años, antes del COVID-19 los espacios iban siendo rediseñados, más por razones de eficiencia. Se podía alquilar oficinas por horas en lugar de meses. Cafeterías que se volvían lugares de lectura y de escritura. Industrias que instalaban gimnasios y lugares de recreación para sus trabajadores, motivados por aumentar su productividad... Antes del COVID-19, las casas no estaban diseñadas para ser espacios escolares o de gimnasio ni las ciudades estaban diseñadas para que haya distanciamiento físico. Con el COVID-19 la arquitectura está desafiada. En esta coyuntura la idea de lo privado va siendo reconceptualizada: casa como espacio de escuela, de trabajo, de reflexión y de gimnasio (ver: Ventura, 2020). ¿Cómo va respondiendo la arquitectura?

\section{Propuestas de arquitecturas}

La arquitectura de emergencia y la arquitectura de crisis son temas que comienza a tomar protagonismo. Se van centrando en la mitigación de enfermedades e incidentes naturales. La sostenibilidad ambiental es parte condicionante, al igual que proyectos más autosuficientes. Es búsqueda de transformar espacios infrautilizados en medio de una economía mundial en aparente recesión.

Hay diversos movimientos que asumen estos retos. Uno de ellos es el concurso de Prototipos de Salud de Emergencia organizado por el Taller de Desarrollo Urbano (Venezuela), la Organización Peruana de Estudiantes de Arquitectura (Perú) y el Colectivo Más Ciudad (Perú). Este concurso se planteó como una oportunidad para generar respuestas arquitectónicas innovadoras para afrontar los posibles colapsos en los sistemas de salud frente a la amenaza del COVID-19 (Maiztegui, 
2020).

El primer premio lo ganó Sofia Martinelli, Antonella Rodríguez Robustelli, Sofia Piñel, Camila Laitán y Nadia Lucía Faccipieri, de la Universidad Nacional de La Plata, Argentina, con el "Prototipo Sanitario de emergencia". El diseño de esta unidad supone una propuesta arquitectónica que solvente la actual emergencia sanitaria frente a la pandemia mundial del COVID-19, con el objetivo de abastecer con equipamiento adecuado las ciudades que así lo requieran. En términos arquitectónicos, la propuesta asume la condición de células aisladas y/o conectadas entre sí, con una gran versatilidad para responder a diversos armados y emplazamientos. Los puntos determinantes de la intervención son:

- Asegurar un montaje sencillo con la mayor rapidez posible y la menor cantidad de operarios.

- Garantizar material de estructura y envolvente en un solo elemento, con la condición de ser de fácil limpieza y desinfección, que tenga durabilidad, resistencia y buen aislamiento.

- Ajustar el prototipo en la medida de posibilitar el transporte de unidades, y adaptabilidad a los diferentes contextos.

La triangulación de la información fue posible mediante el uso de diferentes métodos de recopilación de datos, y así se lograban respaldar los resultados mixtos del estudio entre sí.

Figura 1. Proceso de fabricación de un prototipo sanitario de emergencia.

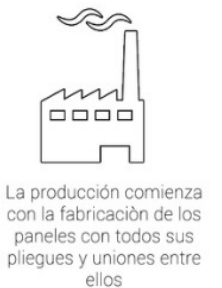

ellos

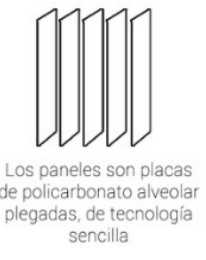

encilla

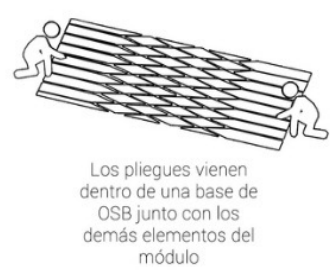

módula
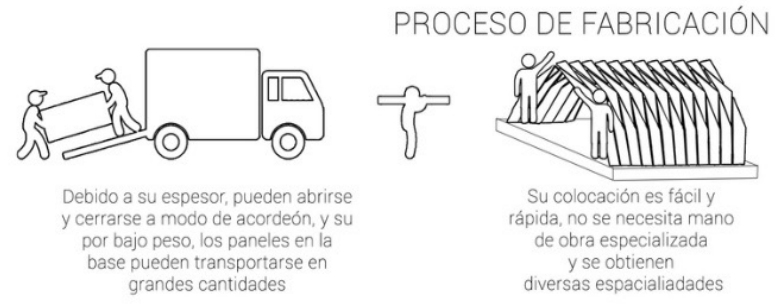

Fuente. Maiztegui, B. (2020, 10 junio). Prototipos de Salud de Emergencia por estudiantes latinoamericanos. Plataforma

También hay un concurso abierto por el BID, de propuesta para "volver a la calle" (BID, 2020), de reactivar los espacios públicos en un escenario de post-pandemia, respetando el distanciamiento físico y recuperando la confianza en el espacio urbano.

A medida de las diferentes fases de la pandemia, se van centrando en espacios "privados". Se empieza a repensar en el concepto de confort en el hogar: desde áreas verdes y jardines, tejados explotables, luz natural y ventilación, balcones y terrazas, etc. En ese re-imaginarse hay que tomar en cuenta a las personas de diferentes edades, por ejemplo la niñez, que en el pasado ya influyó para que ciudades como Amsterdam en los años de 1970 cierren carreteras y abran calles para jugar (Troncoso, 2020). La misma profesión de arquitectura va cambiando, se ve obligada a trabajar de forma más interdisciplinaria, con las ciencias ambientales, médicas, sociales, agrícolas... (Harrouk, 2020)

El primer foco que la arquitectura va apuntado es al rediseño de los espacios públicos, a las ciudades, en particular buscando responder al desafío de la aglomeración (Editorial Construir, 2020). En correspondencia, apuntan a lugares de aglomeración como los aeropuertos, que Rem 
Koolhaas va discutiendo, de en lugar de ser centros comerciales que acorralan a las personas viajantes recupere su utilidad para los viajes (Luscombe, 2020); que los edificios cuenten con aire fresco libre de virus, al igual que parques como pulmones de las ciudades (ver: editorial Construir, 2020).

Los puntos de reinvenciones son: hogar, ciudades adaptables, espacios públicos, densidad, transporte y movilidad, y economía y negocios (Tuero, 2020). Todos ellos en respuesta a las pandemias (Giacobbe, 2020).

Las oficinas en el hogar se han vuelto la solucion inmediata para muchas empresas y coorporaciones. Al respecto, Eliot Potsma y Verda Alexander, en una webcast con Design Disruption $^{1}$, discuten de qué va pasar con las oficinas despues de la pandemia. Verda argumenta que el COVID-19 ha cambiado muchos aspectos del diseño y distribución de espacios en el area de trabajo; ella propone un concepto de "planta libre" (edificios no separados por paredes) para la flexibilidad de multiples cambios en la distribución de muebles y que en la oficina haya una estación de lavado de manos, máscaras. Eliot, por su parte, argumenta que a medida que nos volvamos más flexibles, nos separaremos de la «mesa de oficina perfecta» (cubículos estandarizados) y vamos a adoptar "mesas flexibles" (mesas = áreas o espacios). Un ejemplo de esto último es lo que hizo Google HQ en California, allí dividieron el espacio en 20 «áreas» diferentes que tienen un diseño particular y hacen que equipos y trabajadores se cambien y entren en salas o áreas que les estimulen mejorar sus ideas o tengan mayor comodidad de trabajo.

\section{Mundo rural que convoca a la arquitectura}

Este empuje de la arquitectura obvia el ámbito rural, salvo como la expansión de áreas urbanas sobre las rurales o como "casas de verano". Aquí apuntamos la importancia de una arquitectura rural, que podría inspirar incluso a la arquictectura urbana de las élites tan dominantes a través de los siglos.

Los desafíos tienen que ver con la higiene, un déficit mayor por siglos, una situación que ha sido exagerada además por la discriminación hacia el mundo rural. Esa situación de higiene se debe en parte porque las familias rurales lidian todos los días con la tierra, la agricultura, los agro-químicos, el ganado menor, el destace o el fuego de la cocina, y lo hacen muchas veces sin contar con medidas de protección como los guantes, las botas o las mascarillas, y en parte porque no acceden a información mientras las creencias les guían a no protegerse.

La escasez de agua, de infraestructura básica y de información les ha condicionado en sus vidas. A las mujeres a ir al río a lavar ropa, a gastar poca agua en el lavado de trastes. El carecer de pilas de agua o mangueras suficientes, afecta esos detalles que mueven la vida cotidiana. El poco acceso a información influye en la vida diaria, por ejemplo no suelen lavar los trastes con cloro, trastes que podrían contener la bacteria salmonela que suele encontrarse en alimentos contaminados con heces de animales. Mencionamos estos puntos para ilustrar que las enfermedades y las pandemias diezman con frecuencia a las poblaciones rurales.

La mayoría de las casas rurales, particularmente de las personas con escasos recursos, tienen pisos de tierra, son estructuras cerradas con poca ventilación, donde todo está juntos (la cocina, el dormitorio y la sala), que muchas se duerme "en la cama grande". Por ejemplo, es conocido que el

1 Es espacio virtual donde personas que trabajan en arquitectura reflexionan sobre el futuro de la oficina ante el hecho disruptivo de la pandemia. Design Disruption, en youtube: https://www.youtube.com/watch?v=yGHPGxCLnw4 
mal de chagas, aquella "enfermedad olvidada" porque las industrias farmacéuticas no la han visto rentable desde el s. XX, se da mayormente en casas con techos de paja y grietas en las paredes de barro donde los insectos que provocan esa enfermedad acostumbran vivir ${ }^{2}$. Las casas campesinas son una prolongación de la finca, esa finca muchas veces "invade" a las casas; por ejemplo las gallinas y el cerdo cocinero (o jardinero) se pasean en la sala; se guarda el maíz encima del fogón o en el interior de la casa, mientras los gatos lidian con el acecho de las ratas por el maíz... La finca es la oficina del campesino.

Desde el ámbito urbano suele verse la agricultura o la ecología separada de la higiene en la casa y en la familia. En correspondencia, cualquier yerba les parece suciedad, cualquier casa debe estar en poblados o caseríos, cualquier finca debe ser de monocultivo y cualquier insecto debe combatirse con agroquímicos. Con el ojo urbano cuesta entender que una casa en una finca probablemente es más sana que una ciudad con una industria de reses superpobladas, de pollos o de pavos (chompipes o jolotes), industrias que son verdaderas fábricas de virus.

Necesitamos escudriñar la relación higiene y agricultura, casa y finca y escuela y templo para entender la cultura de higiene en las poblaciones rurales, para luego mirar mejorías y cambios a hacerse. Nuestro reto es repensar los espacios comunitarios desde una perspectiva en que la salud y la economía estén incrustadas una a la otra. Casas en las fincas con materiales que les protejan de las ratas y de los insectos portadoras del mal de chagas, a la vez que sean lugares ventilados, $y$ fincas agroforestales, en comunidades como espacios de alimentación, de reflexión, de inter-acción social, de entretenimiento, de escuela en campo abierto y de acciones colectivas.

¿Cómo puede la arquitectura contribuir a la salud rural? Crece el interés mundial por alimentación orgánica y diversificada, también crece presión porque la tierra, el agua y la biodiversidad sean protegidas. Esto nos empuja a re-entender las casas y sus patios con huertas, re-imaginar fincas, casas y parches de bosques conectadas entre sí. Pensar las fincas como "oficinas", lugares de trabajo embellecidas. Pensar las fincas como lugar de creación, por ejemplo, "pisos" de plantas según flujo de aire y energía solar: el primer piso plantas que se arrastran como la sandía, el segundo piso plantas como las hortalizas, el tercer piso plantas como el frijol, cúrcuma o el arroz, el cuarto piso plantas como el maíz o la yuca, el quinto piso plantas como la papaya, el cacao y el café, el sexto piso plantas como los cítricos y el aguacate, el séptimo piso plantas como el mamón o el tamarindo, etc). Pensar en que cada finca tenga su montaña (su "lunarcito"), que sea espacio de meditación, de caminata y sea el pulmón de las comunidades. Visto así, las fincas son jeroglíficos vivos que revelan la calidad de vida de las personas.

Si las ciudades van siendo repensadas con modos que eviten la aglomeración, se puede diseñar casas en las mismas fincas, sin obligar ni inducir a las familias a aglomerarse en pueblos, asentamientos o caseríos. Ello puede implicar el diseñar microterritorios auto-suficientes o comunidades con habitantes que produzcan y procesen diversidad de productos que profundicen sus conexiones sociales, que en dichos espacios hayan escuelas, centros de salud y espacios recreativos, y que sus caminos tengan en cada lado las variedades de árboles y flores del país expresando belleza y salud humana y natural.

El repensar el área rural puede ayudar a que la arquitectura urbana haga repensar a la población

2 Inspirada en esas realidades y por acciones del Dr. Mazza y su equipo, en 1995 filmaron la película Casas de Fuego. En la película se ilustra la relación entre enfermedad-insecto, casas (ranchos) y la desigualdad social. Ver: https://www.youtube.com/ watch? $=$ =A6yWNBytu3U 
urbana. En lugar de ver el área rural como "selva" y espacio de despojo, densificar las conexiones rural-urbanas, no solo porque el cambio climático y las enfermedades son desafíos globales, sino porque esa conexión puede hacer diferencia en la vida urbana y en la vida rural, de que la naturaleza y la agricultura orgánica entren por ejemplo a las casas urbanas, de reorganizar los paisajes agrarios.

\section{Conclusiones}

La pregunta que nos guió es cómo diseñar ciudades, casas y comunidades que frenen los virus y enfermedades y alarguen la vida humana y natural. A lo largo del artículo hemos revisado la relación salud y arquitectura, y ello nos ha hecho valorar que la prevención de epidemias y pandemias pasa porque la arquitectura innove en el diseño de casas, oficinas, ciudades y comunidades rurales. No es el dinero el motor de la humanidad, el dinero nos conducido a un tipo de vida urbana y rural capaz de producir pandemias. El motor de la humanidad es la salud humana y natural. La arquitectura está interpelada a responder a ese desafío.

¿Qué escenario se viene despues de la pandemia? ${ }^{3}$ Los espacios públicos se moverán hacia una mayor automatización para mitigar el contagio, acelerando el desarrollo de tecnologías sin contacto: puertas automáticas, ascensores activados por voz, entrada de habitación de hotel controlada por teléfono celular, luz manos libres interruptores y controles de temperatura, etiquetas automáticas para maletas... Elementos de construcción: reducción de la cantidad de superficies planas donde los gérmenes pueden asentarse e instalar sistemas de ventilación que permitan eliminar el aire potencialmente contaminado de un área determinada.

A la vez se buscará diseños que, movidos por el criterio de distanciamiento físico, conecten a las personas ${ }^{4}$. Ello llevará a crear espacios abiertos, a enfoques interdisciplinarios e inclusivos, a más colaboración integrando nociones de salud pública y personal, movilidad y transporte, psicología ambiental, biofilia y agricultura. También la noción del diseño prefabricado, con particiones flexibles y livianas crecerá más y quizás se vuelva una norma para tener edificaciones que tengan un alto grado de limpieza e higiene. Finalmente, conceptualizar espacios que crean un ambiente de confort y que se conecte con la naturaleza para dar esa sensación de libertad dentro de las edificaciones.

Para usar menos transporte público, el uso de bicicletas va aumentar (Martínez, 2020). Esto puede ser una oportunidad para que en países del sur se empuje también dicho hábitos, así como montar las bestias y recuperar el hábito de caminar por los parches de bosques tanto de fincas como de reservas forestales.

En el campo y en la ciudad el tema ambiental nos mueve a re-imaginar los espacios. Mirar lo rural como espacio de creación y de inspiración. Mirar en las ciudades, no solo la aglomeración humana, sino también la aglomeración insana de animales y de aves del agro-negocio, que son verdaderas fábricas de virus.

La arquitectura como disciplina está interpelada a dejar de servir solo a las elites, a dejar de soñar

3 Para una perspectiva amplia, ver Pulido (2020)

4 La serie Netflix Sense8 ilustra la necesidad de conectarse, de no aislarse. Esa necesidad se expresa en el desdoblamiento físico, rompiendo distancias físicas. Es una serie que nos ayuda a re-imaginar maneras de colaborar, de ayudar a quien quiere aislarse y ser equipo global. 
solo en "residenciales amuralladas". Que estén al servicio de las elites y de las grandes mayorías. En correspondencia, que su contribución esté precisamente en trabajar con otras disciplinas, más allá del núcleo diseño-arquitectura-ingeniería, incluyendo también las ciencias sociales, las naturales, las médicas y las agronómicas, rompiendo incluso esa muralla con los trabajadores albañiles. Es tiempo también de repensarse.

Desde los países del sur, la arquitectura está desafiada a responder también al ámbito rural, a las comunidades. La arquitectura debe ser movida por la salud, por el cambio climático y por las personas, no solo ser movidas por el baile de los dólares. Invertir en lo común y en lo privado. He ahí el desafío de "pensar fuera de la caja".

\section{Referencias}

BBC News Mundo. (2020, 10 mayo). Coronavirus: cómo las pandemias modificaron la arquitectura y qué cambiará en nuestras ciudades después del covid-19. https://www.bbc.com/mundo/ noticias-52314537?fbclid=IwAR3LCBRj1yh_wEVsG_oMr-HdlD9C2f8AtR_hgG3dCpQkJaPMT_SrbNq3yuA

BID (2020). Ideatón Volver a la Calle: soluciones post-COVID-19 para un nuevo común urbano. https://www.iadb.org/es/desarrollo-urbano-y-vivienda/ideaton-volver-la-calle-soluciones-poscovid19-nuevo-comun-urbano?fbclid=IwAR0h18m3FEvwCyiV3omCyGbaPo_ meyMO5tozvgln0Pn2dtzTd7h3OCapc1Q

Colomina, B. (2019), X-Ray Architecture. Lars Müller Publishers

Domínguez, F. (n.d.), Evolución Del Espacio Interior De La Vivienda. Interiores Domésticos, Vida Privada E Intimidad

Editorial Construir. (2020, 8 abril). ¿Qué cambios traerá el Covid-19 al diseño, arquitectura y la construcción? Revista Construir. https://revistaconstruir.com/que-cambios-traera-el-covid19-al-diseno-arquitectura-y-la-construccion/

Engelmann, L., Henderson, J., \& Lynteris, C. (2019). Plague and the City. Routledge.

Giacobbe, A. (2020, 18 marzo). How the COVID-19 Pandemic Will Change the Built Environment. Architectural Digest. https://www.architecturaldigest.com/story/covid-19-design

Harrouk, C. (2020, 23 mayo). Architecture post COVID-19: the Profession, the Firms, and the Individuals. ArchDaily. https://www.archdaily.com/939534/architecture-post-covid-19-theprofession-the-firms-and-the-individuals

Luscombe, B. (2020, 14 mayo). Architect Rem Koolhaas Says Redesigning Public Spaces Was Necessary Before the Pandemic. Time. https://time.com/5836599/rem-koolhaas-architecture-coronavirus/

Maiztegui, B.(2020, 10 junio). Prototipos de Salud de Emergencia por estudiantes latinoamericanos. Plataforma Arquitectura. https://www.plataformaarquitectura.cl/cl/940519/prototipos-de-salud-de-emergencia-por-estudiantes-latinoamericanos\#

Martínez, M. R. (2020, 7 julio). Las ciudades post-coronavirus: así va a transformar la pandemia el diseño urbano. euronews. https://es.euronews.com/2020/05/01/las-ciudades-post-corona- 
virus-asi-va-ha-transformar-la-pandemia-el-diseno-urbano

Pham, D. (2013, 31 diciembre). How Kitchen Design Has Evolved Over the Last Century. Inhabitat - Green Design, Innovation, Architecture, Green Building. https://inhabitat.com/how-kitchen-design-has-evolved-over-the-last-century/

Pulido, N. (2020, 13 mayo). Así será la arquitectura poscoronavirus. abc. https://www.abc.es/cultura/arte/abci-sera-arquitectura-poscoronavirus-202005070138_noticia.html?ref=

Troncoso, U. (2020, 11 junio). Ciudades imposibles: la perspectiva de los niños y niñas sobre la pandemia de COVID-19. Plataforma Arquitectura. https://www.plataformaarquitectura. cl/cl/941462/ciudades-imposibles-la-perspectiva-de-los-y-las-ninas-sobre-la-pandemia-decovid-19

Tuero, L. (2021, 23 agosto). La nueva normalidad en arquitectura. Blog de DSIGNO. https://www. dsigno.es/blog/diseno-de-interiores/la-nueva-normalidad-en-arquitectura-o-como-el-covid19-lo-cambio-todo 